\title{
Dark forecast for mental health in Alberta
}

$\mathrm{S}$ ervice providers and mental health professionals across Alberta report an increase in the number of people seeking care for mental health issues, a spike some have linked to an economy devastated by low oil prices.

"The mental health situation here is messed up," says Jennifer Best, the senior director of community programs at a YMCA in Fort McMurray. "We are seeing and hearing about more and more people with mental health problems and crises."

While hard data on the increase is not available, Best notes that, according to a survey done last year by the Canadian Index of Wellbeing at the University of Waterloo, almost 3\% of respondents in Fort McMurray reported they had poor mental health, compared to the national average of just over $1 \%$.

What makes the mental health situation in Fort McMurray even worse, according to Best, is that there are not enough local mental health services, particularly for those in urgent need of care.

"Don't have your mental health crisis here anytime outside of Monday to Friday, 8 am to 4 pm," she notes dryly.

As well, the nature of much of the work in oil and gas in northern Alberta precludes some workers from taking medications to treat any mental health issues that may be facing, says Best. "It's difficult to medicate when your job essentially requires you to be drug-free," she says.

Another problem is that the Alberta industries most affected by the downturn, oil and gas, are generally dominated by men, notes David Grauwiler, executive director of the Alberta division of the Canadian Mental Health Association.

"Men, of course, have hidden issues related to the stigma around depression and anxiety," says Grauwiler. "Men in these industries have questions around their self-worth and their visibility in society."

Of course, the impacts on mental health extend far beyond just the men

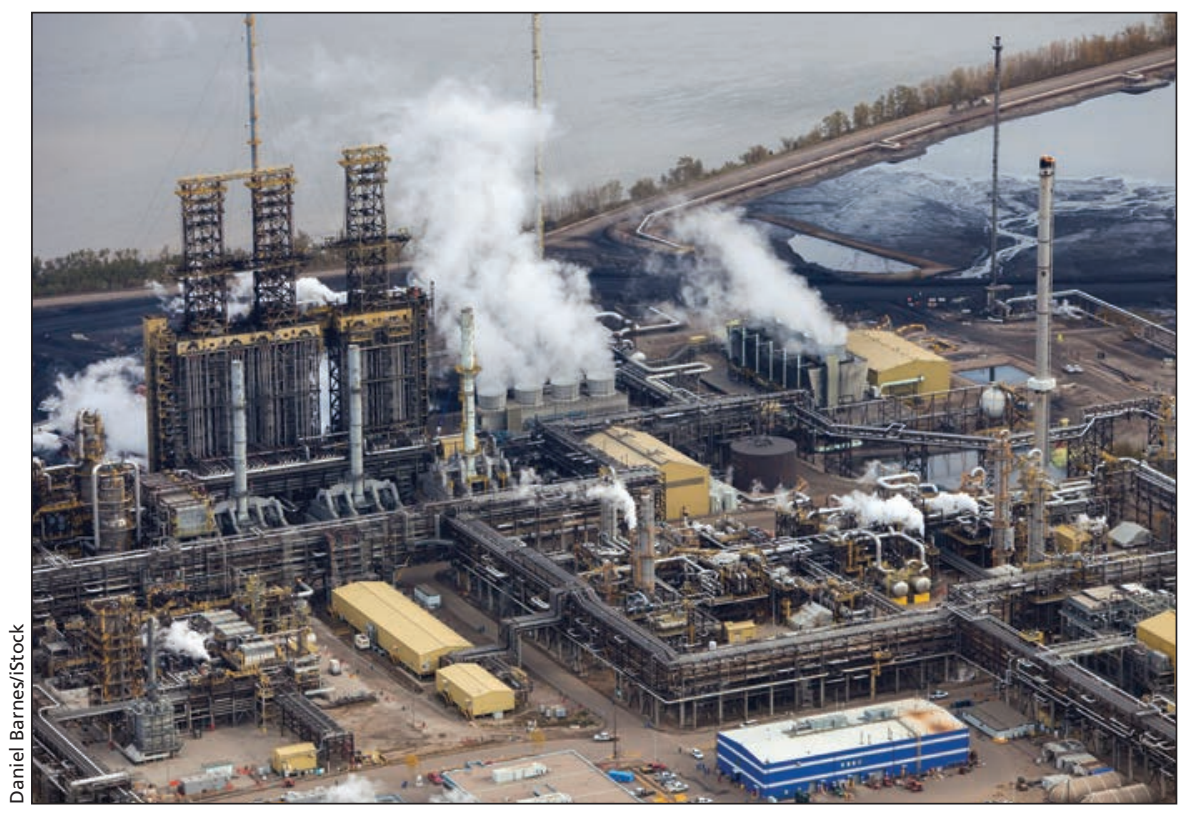

Most workers in Alberta's struggling oil and gas industry are men, who tend to have hidden issues about the stigma around depression and anxiety.

who work in these industries, notes Grauwiler; it also affects their families, friends and the communities around them, and it is not easy to get the services they need. "It's a long and arduous wait to get into provincial mental health services," he warns.

"It's much harder for us to see where people are getting their support."

Down in Calgary, Meghan Reid has seen client after client trying to cope with the impact of the economic downturn, including many who have not actually lost their jobs. Reid, a provisionally registered psychologist and counsellor at Calgary Career Counselling, says that many of the clients they see are employed but dealing with "survivor guilt."

"They think "why did Joe get laid off? He has a family and I don't, and I have savings, too. Why not me?"' she says. This has become worse over the past year, she says, and clients with survivor guilt deal with it for months after coworkers are let go.

The economic downturn has also caused changes in work environments. This, according to Reid, has also had a negative mental health impact.
"We have a subset of clients that think they wanted a career change, but what they realize after talking with us is that it was actually the environment they were in that they didn't like," says Reid.

"Workloads have increased, morale has decreased and companies are spending less money on employee development," she says. "People tend to become unhappy."

On top of this, Reid notes, many people move to Alberta for work and, as a result, do not have many friends or family around them to help them deal with any mental health issues.

"A lot of people are here alone," says Reid. "They have no social support system."

Based on what she has seen over the past year, Reid does not expect the situation to get better anytime soon.

"We've seen downturns before, but this one is unique," she says. "There isn't a clear-cut end to it. Nobody's really sure when it's going to subside." - Michael Colborne, Edmonton, Alta.

CMAJ 2016. DOI:10.1503/cmaj.109-5207 